\title{
Psychiatric diagnoses and punishment for misconduct: the effects of PTSD in combat- deployed Marines
}

\author{
Robyn M Highfill-McRoy ${ }^{1 * \dagger}$, Gerald E Larson ${ }^{1 \dagger}$, Stephanie Booth-Kewley ${ }^{1 \dagger}$, Cedric F Garland ${ }^{1,2+}$
}

\begin{abstract}
Background: Research on Vietnam veterans suggests an association between psychological problems, including posttraumatic stress disorder (PTSD), and misconduct; however, this has rarely been studied in veterans of Operation Iraqi Freedom or Operation Enduring Freedom. The objective of this study was to investigate whether psychological problems were associated with three types of misconduct outcomes (demotions, drug-related discharges, and punitive discharges.)

Methods: A population-based study was conducted on all U.S. Marines who entered the military between October 1, 2001, and September 30, 2006, and deployed outside of the United States before the end of the study period, September 30, 2007. Demographic, psychiatric, deployment, and personnel information was collected from military records. Cox proportional hazards regression analysis was conducted to investigate associations between the independent variables and the three types of misconduct in war-deployed $(n=77998)$ and non-war-deployed ( $n=13$ 944) Marines.
\end{abstract}

Results: Marines in both the war-deployed and non-war-deployed cohorts with a non-PTSD psychiatric diagnosis had an elevated risk for all three misconduct outcomes (hazard ratios ranged from 3.93 to 5.65). PTSD was a significant predictor of drug-related discharges in both the war-deployed and non-war-deployed cohorts. In the war-deployed cohort only, a specific diagnosis of PTSD was associated with an increased risk for both demotions (hazard ratio, 8.60; 95\% confidence interval, 6.95 to 10.64) and punitive discharges (HR, 11.06; 95\% Cl, 8.06 to 15.16).

Conclusions: These results provide evidence of an association between PTSD and behavior problems in Marines deployed to war. Moreover, because misconduct can lead to disqualification for some Veterans Administration benefits, personnel with the most serious manifestations of PTSD may face additional barriers to care.

\section{Background}

Numerous studies have demonstrated that exposure to combat or other traumatic events is associated with an increase in psychiatric problems, including depression, substance abuse, anxiety disorders, and posttraumatic stress disorder (PTSD) [1-3]. Another area of concern is the relationship between combat exposure and antisocial behavior. The media have keenly focused on this topic, as evidenced by the publicity surrounding military misconduct both during and after deployment [4-7].

\footnotetext{
* Correspondence: Robyn.McRoy@med.navy.mil

+ Contributed equally

'Behavioral Science and Epidemiology Program, Naval Health Research

Center, San Diego, California, USA

Full list of author information is available at the end of the article
}

Research on Vietnam War veterans strongly suggests an association between combat exposure and antisocial and high-risk behaviour [8-11]. Boscarino (1981) found that Vietnam veterans and Vietnam-era veterans had higher levels of drug abuse than non-veterans, after adjusting for demographic factors [8]. Yager, Laufer, and Gallops (1984) found that participation in violence during the Vietnam War was associated with a heightened risk of arrests and convictions, after controlling for preservice factors [9]. Beckham et al (1997) reported that exposure to atrocities during the Vietnam War heightened the risk of engaging in interpersonal violence post-war [10]. Another study found that combat exposure level in Vietnam veterans was associated with post war antisocial behavior, including illegal activities, 
relationship problems, relationship problems, and reckless driving [11].

Other studies examining the relationship between combat and antisocial behavior have focused on more recent military conflicts [12-15]. Rothberg et al (1994) found that U.S. Army units that deployed during the Persian Gulf War had higher rates of drug and alcohol service use than did non-deployed units [12]. The 2005 Department of Defense Survey of Health Related Behaviors found that approximately $16-18 \%$ of Marines who served in Operation Iraqi Freedom, Operation Enduring Freedom, or other operations reported illegal drug use during the past year, compared with $9 \%$ of those who did not serve in any operation [13]. Killgore et al (2008) found that Operation Iraqi Freedom soldiers exposed to violent combat reported more aggressive behaviors following deployment, including angry outbursts, destroying property, and threatening others with violence [14].

It has been proposed that PTSD could mediate the relationship between combat and subsequent antisocial behaviour [16-19]. However, research on this topic has produced conflicting findings. Some studies have found that veterans with combat-related PTSD report higher rates of interpersonal violence, incarcerations, and drug use/dependence, compared with veterans without PTSD [10,20-22]. However, not all studies have identified an association between combat-related PTSD and these outcomes [23-25].

The inconsistent findings may be due to methodological differences in the research. For example, studies have relied on retrospective $[10,19,25]$ and cross-sectional $[3,26]$ study designs, most likely due to the uncommon occurrence of both the risk factor (trauma resulting in a PTSD diagnosis) and the outcome (misconduct). As a result, the temporal order of events usually was not examined. Case definitions were not consistent across studies and were based on a variety of methods, including a positive result on a symptombased checklist or survey $[11,18]$, an interview-based diagnosis $[16,25]$, or hospitalization for PTSD $[19,23]$. Combat veterans were often compared with dissimilar control groups, such as non-deployable personnel or non-veterans, who may have different rates of misconduct outcomes. Outcomes differed substantially across studies making it difficult to make comparisons between studies. Lastly, research in this area has generally focused on veterans of the Vietnam and Gulf wars, and only a few studies have examined psychiatric disorders and misconduct in contemporary combatants.

\section{Objectives}

The goal of this study was to use a population-based approach to examine the relationships between combat deployment, psychiatric problems including PTSD, and misconduct outcomes. The objectives of this study were to ascertain and compare incidence rates of three types of misconduct outcomes (demotions, drug-related discharges, and non-drug-related punitive discharges) among two military cohorts (war-deployed and nonwar-deployed Marines), and to determine if having a psychiatric diagnosis, including PTSD, was associated with misconduct.

\section{Methods}

\section{Subjects}

A population-based cohort study was conducted among all active-duty, enlisted Marine Corps personnel who first entered the military between October 1, 2001, and September 30, 2006. To be eligible for this study, Marines had to have been enlisted for longer than 6 months and deployed to either Iraq, Afghanistan, or Kuwait (war deployed Marines) or to another location outside of the United States without receiving hazardous duty pay (non-war-deployed Marines) before the end of the study period, September 30, 2007. The analyses were limited to active-duty Marines because medical data were not consistently available for reservists.

Excluded from the study were individuals who served less than 6 months of service, did not deploy before the end of the study period, changed military branches during the study time frame, or received hazardous duty pay but did not deploy to Iraq, Afghanistan, or Kuwait. Officers and warrant officers were excluded because they constituted an extremely small portion of personnel who received a misconduct outcome during this time frame.

This research was conducted in compliance with all applicable federal regulations governing the protection of human subjects in research. The Naval Health Research Center Institutional Review Board approved this study (protocol NHRC.2005.0003).

\section{Data sources and variables}

Personnel, demographic, and deployment information collected from the Defense Manpower Data Center (DMDC) and medical information collected from the TRICARE Management Activity were used to construct the longitudinal database for this study. Demographic and personnel predictors included sex, race (Caucasian, African American, Hispanic, or other), date of military entry, accession age (age at military entry,) and Armed Forces Qualification Test (AFQT) cognitive ability score. AFQT was divided into tertiles based on the distribution of scores (low: 0-50, medium: 51-70, and high: 71-100). Age at military entry was dichotomized based on the mean of the distribution $(<19, \geq 19$ years).

Deployment information included dates and country of deployment. Individuals were categorized as being 
war deployed if they received a combat zone tax exclusion or hazardous duty/imminent danger pay and were deployed to Iraq, Kuwait, or Afghanistan before the end of the study period ( $\mathrm{n}=77$ 998.) Personnel whose duty station was outside of the United States and who did not receive hazardous duty pay were classified in the deployed, non-war-deployed cohort $(\mathrm{n}=13$ 944.)

The three outcomes of the study (demotions, drugrelated discharges, and non-drug-related punitive discharges) and the dates of their occurrence were obtained from DMDC. Individuals were classified as demoted if official records indicated a lowering of their paygrade. Individuals were classified as having a drug discharge if they were discharged and their separation code description included drug use or abuse. Individuals were classified as having a non-drug-related punitive discharge if they were discharged and their separation code description included frequent involvement with civil or military authorities, court martial or action in lieu of court martial, or a civil or military conviction. This last outcome measure reflects the most severe instances of blatant criminal conduct. In order to classify individuals into the appropriate deployment cohort, all outcomes included in the analyses had to have occurred after a deployment.

Information on inpatient and outpatient medical visits were obtained from Tricare Management Activity, the Department of Defense's health care system. This database includes treatment dates and clinical diagnoses by credentialed providers (including psychiatrists, psychologists, and medical doctors) at both military treatment facilities and government-reimbursed private providers. These direct care records are generated for military personnel on every medical encounter, with the exception of medical encounters that occurred in a war zone or via civilian providers who were not reimbursed through TRICARE.

Individuals were defined as having a PTSD diagnosis if medical records included an International Classification of Diseases, Ninth Revision, Clinical Modification (ICD9-CM) diagnosis code of 309.81. This definition is based on meeting the criteria stipulated in the Diagnostic and Statistical Manuel of Mental Disorders IV (Text Revision) (DSM-IV-TR). and is consistent irrespective of individual combat experiences [27].

Individuals were defined as having a psychiatric diagnosis (excluding PTSD) if their medical records included an ICD-9-CM diagnosis code in the range of 290 and 316 , with the exception of 305.1 (tobacco use disorders), 309.81 (PTSD), and 292 and 305.2 to 305.9 (druginduced mental disorders and drug abuse). Psychiatric diagnoses were made using standard DSM-IV criteria. Psychiatric diagnoses (including PTSD) that occurred after the misconduct outcome event were not included.

\section{Statistical analyses}

Frequency distributions for each risk factor and outcome were obtained and stratified by deployment cohort. Categorical variables were analyzed using the chi-square test and continuous variables were analyzed using $t$-tests.

Three separate Cox proportional hazards regression models were used to determine associations between the independent variables (deployment cohort, psychiatric diagnosis status, AFQT score, sex, race/ethnicity, and accession age) on time to each misconduct outcome (demotions, drug-related discharges, and non-drugrelated punitive discharges). Cox regression is a type of survival analysis that is used for modeling the effects of several independent variables upon the time to a specific event [28]. In our study, the advantage of using Cox regression is that is allows data from all participants to be included in the calculation of the three misconduct models, even though subjects entered and discharged from the military at different time points during the study period. For each service member in the study, the observation period started at time of entry into boot camp and continued until he or she had a misconduct outcome, was discharged from the military, or died. In each analysis, Marines who did not have the outcome before the end of the observation period were right censored (meaning that outcomes occurring after the end of the observation period were considered missing.)

Regression diagnostics were performed, and no substantial collinearities were detected among model variables (all correlations were $\leq .20$ ). With the exception of psychological diagnosis status, all risk factors met the proportional hazards assumption. Because the time interval between entering the Marine Corps and receiving a psychiatric or PTSD diagnosis (if applicable) was different for each participant, psychiatric diagnosis status was treated as a segmented time-dependent covariate in the Cox regression. All individuals were classified as having "no diagnosis" at the start of the study and changed to either "psychiatric diagnosis" or "PTSD diagnosis" at the month of their first diagnosis. Once classified as having PTSD, that classification became final until the end of study.

Univariate analyses were performed using Cox proportional hazards regression. All variables that were significant in the univariate analysis $(\mathrm{p}<0.05)$ were entered into a general adjusted Cox regression model. From the general model, a reduced and final model was obtained for each misconduct outcome using a manual, backward, stepwise elimination approach using an alpha cutoff level of $\leq 0.05$.

Analyses included testing for interaction among psychiatric status and deployment cohort using the likelihood ratio test. Because effect modification between 
deployment cohort and psychiatric status was statistically confirmed in all misconduct models, the three Cox regression models were stratified by deployment cohort. For all analyses, a two-tailed alpha cutoff level of $\leq 0.05$ was considered statistically significant. All analyses were performed using SPSS, version 16.0 (SPSS Inc., Chicago, Illinois, USA).

\section{Results}

Of the 164 764 Marines who first enlisted during the study period, 91825 fulfilled the study inclusion criteria (table 1). The study population for both the drug-related discharge and punitive discharge models each included 13944 non-war-deployed and 77881 war-deployed personnel. The demotions model consisted of 13721 nonwar-deployed and 74 998 war-deployed personnel. The study population for the demotions model was smaller than for the two discharge models because 3106 Marines were demoted before ever deploying, making them ineligible for inclusion in either cohort in the demotions model.

Personnel in the war-deployed cohort were significantly more likely to be male, Caucasian, and have a low AFQT score (table 1). Individuals in the wardeployed cohort were significantly more likely to have either no psychiatric diagnosis, or a PTSD diagnosis, while individuals in the non-war-deployed cohort were significantly more likely to have a non-PTSD psychiatric diagnosis (table 2). The incidence of the three
Table 2 Psychiatric and Misconduct Outcomes in WarDeployed and Non-War-Deployed Enlisted Marines Corps Personnel, 2001-2007 ${ }^{\dagger}$

\begin{tabular}{|c|c|c|}
\hline \multirow[t]{2}{*}{ Characteristic } & $\begin{array}{l}\text { Non-war- } \\
\text { deployed }\end{array}$ & War deployed \\
\hline & $\begin{array}{c}N(\%) n=13 \\
944\end{array}$ & $\begin{array}{c}N(\%) n=77 \\
881\end{array}$ \\
\hline \multicolumn{3}{|l|}{ Psychiatric diagnosis status } \\
\hline No diagnosis & $11289(81.0)$ & $66577(85.5)^{* *}$ \\
\hline $\begin{array}{l}\text { Psychiatric diagnosis without } \\
\text { PTSD }\end{array}$ & $2584(18.5)$ & $8979(11.6)^{* *}$ \\
\hline PTSD diagnosis & $73(0.5)$ & $2325(3.0)^{* *}$ \\
\hline \multicolumn{3}{|l|}{ Length of service at first diagnosis } \\
\hline Mean & 20.6 & $25.6^{* *}$ \\
\hline SD & 12.7 & 14.9 \\
\hline \multicolumn{3}{|l|}{ Misconduct outcomes } \\
\hline Demotion & $1300(9.7)$ & $4692(6.5)^{* *}$ \\
\hline Drug-related discharge & $250(1.8)$ & $1148(1.5)^{* *}$ \\
\hline Punitive discharge & $184(1.4)$ & $358(0.5)^{* *}$ \\
\hline
\end{tabular}

PTSD, posttraumatic stress disorder.

*Statistically different from the non-war-deployed reference group $(p<0.05)$.

**Statistically different from the non-war-deployed reference group $(p<0.01)$.

misconduct outcomes were higher in Marines deployed outside combat zones than in those deployed to combat zones (table 2).

All independent variables were significant in the univariate analyses $(\mathrm{p}<0.05)$ and were entered into the multivariate models. High AFQT score and female sex were inversely associated with all three misconduct

Table 1 Demographic Characteristics in Three Groups of Marines Corps Personnel, 2001-2007

\begin{tabular}{|c|c|c|c|}
\hline \multirow[t]{2}{*}{ Characteristic } & Non-war deployed & War deployed & Excluded from study sample \\
\hline & $N(\%) n=13944$ & $N(\%) n=77881$ & $N(\%) n=72939$ \\
\hline \multicolumn{4}{|l|}{ Accession age } \\
\hline$<19$ years & $6795(48.7)$ & $37698(48.4)$ & $32719(44.9)^{* *}$ \\
\hline$\geq 19$ years & $7149(51.3)$ & $40183(51.6)$ & $40219(55.1)^{* *}$ \\
\hline \multicolumn{4}{|l|}{ Sex } \\
\hline Male & $12296(88.2)$ & $74962(96.3)^{* *}$ & $65780(90.2)^{* *}$ \\
\hline Female & $1648(11.8)$ & $2919(3.7)^{* *}$ & $7159(9.8)^{* *}$ \\
\hline \multicolumn{4}{|l|}{ Race/ethnicity } \\
\hline Caucasian & $9050(64.9)$ & $55942(71.8)^{* *}$ & $54191(74.3)^{* *}$ \\
\hline African American & $1653(11.9)$ & $5504(7.1)^{* *}$ & $5554(7.6)^{* *}$ \\
\hline Hispanic & $2171(15.6)$ & $11150(14.3)^{* *}$ & $7524(10.3)^{* *}$ \\
\hline Other/mixed/missing & $1070(7.7)$ & $5285(6.8)^{* *}$ & $5670(7.8)$ \\
\hline \multicolumn{4}{|l|}{ AFQT score } \\
\hline Low $(0-50)$ & $4047(29.0)$ & $26409(33.9)^{* *}$ & $21276(29.2)^{* *}$ \\
\hline Medium (51-70) & $5006(35.9)$ & $26860(34.5)^{* *}$ & $26291(36.0)^{* *}$ \\
\hline High (71-99) & 4891 (35.1) & $24612(31.6)^{* *}$ & $24992(34.3)^{* *}$ \\
\hline
\end{tabular}

AFQT, Armed Forces Qualification Test.

${ }^{\dagger}$ Individuals who served $<6$ months of service, were an officer or a warrant officer, did not deploy before the end of the study period, changed military branches during the study time frame (such as from the Marines to the Army), or received hazardous duty pay but did not deploy to Iraq, Afghanistan, or Kuwait, were not eligible for the study.

*Statistically different from the non-war-deployed reference group $(p<0.05)$.

**Statistically different from the non-war-deployed reference group $(p<0.01)$. 
Table 3 Multivariate Cox Proportional Hazards Regression Analysis Examining Associations of Psychiatric Diagnosis Status and Drug-Related Discharges in Two Cohorts of Marine Corps Personnel, 2001-2007

\begin{tabular}{|c|c|c|c|c|}
\hline & \multicolumn{2}{|c|}{ Non-war deployed $n=13944$} & \multicolumn{2}{|c|}{ War deployed $n=77881$} \\
\hline & HR & $95 \% \mathrm{Cl}$ & HR & $95 \% \mathrm{Cl}$ \\
\hline \multicolumn{5}{|l|}{ Psychiatric diagnosis status } \\
\hline No psychiatric diagnosis & 1.00 & & 1.00 & \\
\hline Psychiatric diagnosis without PTSD & $5.65^{* *}$ & 4.37 to 7.29 & $5.22^{* *}$ & 4.59 to 5.94 \\
\hline PTSD diagnosis & $5.72^{* *}$ & 1.80 to 18.19 & $8.60^{* *}$ & 6.95 to 10.64 \\
\hline \multicolumn{5}{|l|}{ AFQT score } \\
\hline Low $(0-50)$ & 1.00 & & 1.00 & \\
\hline Medium (51-70) & 0.77 & 0.59 to 1.02 & $0.79^{* *}$ & 0.69 to 0.90 \\
\hline High (71-99) & $0.37^{* *}$ & 0.26 to 0.52 & $0.46^{* *}$ & 0.39 to 0.54 \\
\hline \multicolumn{5}{|l|}{ Sex } \\
\hline Male & 1.00 & & 1.00 & \\
\hline Female & $0.51^{* *}$ & 0.33 to 0.77 & $0.40^{* *}$ & 0.24 to 0.55 \\
\hline \multicolumn{5}{|l|}{ Race/ethnicity } \\
\hline Caucasian & 1.00 & & 1.00 & \\
\hline African American & 0.85 & 0.59 to 1.23 & $1.73^{* *}$ & 1.46 to 2.05 \\
\hline Hispanic & $0.41^{* *}$ & 0.26 to 0.65 & $0.63^{* *}$ & 0.52 to 0.77 \\
\hline Other/mixed/missing & 0.71 & 0.42 to 1.18 & $0.75^{*}$ & 0.57 to 0.98 \\
\hline \multicolumn{5}{|l|}{ Accession age } \\
\hline$<19$ years & 1.00 & & 1.00 & \\
\hline$\geq 19$ years & 1.01 & 0.79 to 1.30 & 0.91 & 0.81 to 1.02 \\
\hline
\end{tabular}

AFQT, Armed Forces Qualification Test; $\mathrm{Cl}$, confidence interval; HR, hazard ratio; PTSD, posttraumatic stress disorder. ${ }^{*} p<0.05$

${ }^{* *} \mathrm{p}<0.01$

Table 4 Multivariate Cox Proportional Hazards Regression Analysis Examining Associations of Psychiatric Diagnosis Status and Punitive Discharges in Two Cohorts of Marine Corps Personnel, 2001-2007

\begin{tabular}{|c|c|c|c|c|}
\hline & \multicolumn{2}{|c|}{ Non-war deployed $n=13944$} & \multicolumn{2}{|c|}{ War deployed n = 77881} \\
\hline & HR & $95 \% \mathrm{Cl}$ & HR & $95 \% \mathrm{Cl}$ \\
\hline \multicolumn{5}{|l|}{ Psychiatric diagnosis status } \\
\hline No psychiatric diagnosis & 1.00 & & 1.00 & \\
\hline Psychiatric diagnosis without PTSD & $5.63^{* *}$ & 4.18 to 7.58 & $5.20^{* *}$ & 4.11 to 6.58 \\
\hline PTSD diagnosis & 2.88 & 0.40 to 20.79 & $11.06^{* *}$ & 8.06 to 15.16 \\
\hline \multicolumn{5}{|l|}{ AFQT score } \\
\hline Low (0-50) & $1.00^{*}$ & & 1.00 & \\
\hline Medium (51-70) & 0.76 & 0.54 to 1.05 & $0.66^{* *}$ & 0.52 to 0.83 \\
\hline High (71-99) & $0.48^{* *}$ & 0.33 to 0.72 & $0.45^{* *}$ & 0.33 to 0.60 \\
\hline \multicolumn{5}{|l|}{ Sex } \\
\hline Male & 1.00 & & 1.00 & \\
\hline Female & $0.52^{* *}$ & 0.32 to 0.84 & $0.38^{* *}$ & 0.19 to 0.77 \\
\hline \multicolumn{5}{|l|}{ Race/ethnicity } \\
\hline Caucasian & 1.00 & & 1.00 & \\
\hline African American & $2.29^{* *}$ & 1.60 to 3.28 & $2.45^{* *}$ & 1.85 to 3.25 \\
\hline Hispanic & 0.99 & 0.64 to 1.54 & 1.08 & 0.80 to 1.45 \\
\hline Other/mixed/missing & 1.16 & 0.66 to 2.02 & 1.23 & 0.81 to 1.88 \\
\hline \multicolumn{5}{|l|}{ Accession age } \\
\hline$<19$ years & 1.00 & & 1.00 & \\
\hline$\geq 19$ years & 1.20 & 0.90 to 1.61 & $0.69^{* *}$ & 0.56 to 0.85 \\
\hline
\end{tabular}

AFQT, Armed Forces Qualification Test; $\mathrm{Cl}$, confidence interval; $\mathrm{HR}$, hazard ratio; PTSD, posttraumatic stress disorder. ${ }^{*} p<0.05$.

${ }^{* *} \mathrm{p}<0.01$ 
outcomes in both cohorts (tables 3 and 4; see Additional file 1). Compared with personnel with no diagnosis, non-PTSD psychiatric diagnoses were positively associated with all three outcomes. African Americans were at a higher risk for the three misconduct outcomes, with the exception of drug-related discharges among nonwar-deployed personnel.

Deployment to war was not associated with an increased risk of a drug-related discharge (table 2). In the non-war-deployed cohort, Marines with PTSD were 5.7 times as likely to have a drug-related discharge compared with Marines without a psychiatric diagnosis, after adjusting for all other covariates in the model ( $\mathrm{p}<0.01$; 95\% confidence interval [CI], 1.80 to 18.19) (table 3). In the war-deployed cohort, Marines with PTSD were 8.6 times as likely to have a drug-related discharge compared with Marines without a psychiatric diagnosis, after adjusting for other covariates in the model $(\mathrm{p}<0.01$; 95\% CI, 6.95 to 10.64) (table 3).

General psychiatric diagnoses increased the risk for a punitive discharge in both cohorts, but PTSD diagnoses only increased the risk for a punitive discharge in the war-deployed cohort (table 4). Marines in the wardeployed cohort who had a PTSD diagnosis were 11.1 times more likely to have a misconduct discharge compared with their peers who did not have a psychiatric diagnosis ( $\mathrm{p}<0.01$; 95\% CI, 8.06 to 15.16).

In both cohorts, a psychiatric diagnosis was associated with an increased risk of a demotion, after controlling for demographic predictors (in the non-war-deployed cohort hazard ratio, 4.5; 95\% CI, 4.03to 5.03; in the wardeployed cohort HR, 3.9; 95\% CI, 3.68 to 4.20; see Additional file 1). However, a PTSD diagnosis was only significantly related to a demotion in the war-deployed cohort; individuals with a PTSD diagnosis were 5.8 times more likely to have a demotion compared with Marines without a psychiatric diagnosis.

\section{Discussion}

The main goal of this study was to examine the associations between psychiatric diagnoses, PTSD, and misconduct outcomes among war-deployed and nonwar-deployed Marines. The incidence rate of PTSD diagnoses in the war-deployed cohort was $3.0 \%$, which is comparable with other studies among active duty personnel that use diagnoses as inclusion criteria (as opposed to PTSD symptom checklists.) [29]. This study found that for both cohorts, Marines with a non-PTSD psychiatric diagnosis had an elevated risk for all three misconduct outcomes (demotions, drugrelated discharges, and non-drug-related punitive discharges). A specific diagnosis of PTSD was also associated with an increased risk for all three misconduct outcomes, but only in the war-deployed cohort. In the non-war-deployed cohort, PTSD was a significant predictor in only one of the three misconduct outcomes (drug-related discharges).

The finding that PTSD increased the risk of drugrelated discharges for all Marines is consistent with other literature, and a number of theories have been posited to explain the relationship, including the selfmedication hypothesis, the sensation-seeking hypothesis, and the susceptibility hypothesis $[25,30,31]$. Individuals with comorbid PTSD and substance abuse problems are at an increased risk for interpersonal violence, imprisonment, and homelessness [32-34]. Therefore, our results provide more evidence for the importance of drug abuse screening and counseling among service members with PTSD.

Our study also revealed that PTSD increased the risk for demotions and punitive discharges in war deployers only. One possible explanation for this finding is that war deployers may have relatively higher levels of PTSD symptoms. This explanation would be consistent with a recent finding that military veterans with combat-related PTSD reported more severe symptoms on the Trauma Symptom Inventory than did crime victims with PTSD [35]. Data from the National Vietnam Veterans Readjustment Study showed that specific types of combat exposure were associated with higher PTSD scores [36]. For example, PTSD scores were significantly higher for those who said they had killed compared with those who had said they had not killed [36].

Beckham et al (1998) also found that exposure to atrocities was associated with higher PTSD symptom levels, even after controlling for combat exposure [26]. Iversen et al (2008) found that United Kingdom military personnel deployed to Iraq who felt their life had been threatened were significantly more likely to have high levels of PTSD symptoms compared with personnel who did not feel their life had been threatened [37]. These findings suggest that psychological and behavioral responses to trauma may be specific to the type of trauma experienced. Compared with other types of traumas, the experience of combat has also been shown to be related to both distinct PTSD symptom profiles and increased aggressive behaviour [10,14,36,38,39], both of which could explain the increased behavioral problems in the war-deployed cohort.

The finding of greatest concern in this study is that combat deployed Marines with a PTSD diagnosis were over 11 times more likely to engage in the most serious forms of misconduct than were combat deployed Marines without a psychiatric diagnosis. This finding is similar to results by Noonan and Mumola (2007), who found that compared with other prisoners, military veterans in prison were less likely to report mental health problems but were more likely to be incarcerated 
for violent offenses than were other prisoners [40]. In another study of veterans who deployed to the first Gulf War (August 1990 to February 1991), Black et al (2005) found that incarcerated veterans were 3.6 times more likely to report PTSD symptoms than were nonincarcerated veterans [20]. Future research should examine the reasons that combat veterans with PTSD are at a higher risk for serious misconduct problems and develop interventions to reduce behavioral problems. Such research is critical, because serious misconduct may lead to disqualification for some Veterans Administration benefits. In addition, personnel with the most serious manifestations of PTSD may face additional barriers to care.

Some military studies examining Navy personnel have found that African Americans have higher rates of involvement in the military's discipline system compared to Caucasians [41-44]. Our study replicated this finding and identified that African Americans in the wardeployed cohort were at an increased risk for all three outcomes compared with Caucasians. In addition, African Americans in the non-war-deployed cohort were also at an increased risk of two types of misconduct: punitive discharges and demotions. More research is required to explore possible factors that moderate this relationship, such as previous trauma exposure, socioeconomic status, and military occupation.

The interpretation of these findings is limited by multiple factors. First, cases were identified from service utilization records and were restricted to treatment seeking individuals who had a psychiatric or PTSD diagnosis, and it is likely that additional personnel had symptoms without an official clinical diagnosis. Also, combat deployers are likely made aware of and encouraged to seek psychological care if they are experiencing symptoms at a higher rate than non-deployed personnel. Our study only included misconduct outcomes that were measurable in personnel records, so the relationship between PTSD and undocumented types of misconduct remains unclear. Only Marines were included in the study, so the findings may not generalize to other military populations. Also, subjects only contributed time to our study while they were on active duty. As a result, questions remain about misconduct in veterans who have left the service. Lastly, PTSD was a relatively uncommon event in the non-war-deployed cohort, and this may have made it more difficult to detect significant associations.

\section{Conclusions}

Overall, the results of this study confirm that combat veterans with PTSD and other psychiatric diagnoses have an elevated risk of misconduct outcomes after diagnosis. In addition to treating psychiatric symptoms, mental health treatment providers should address the effect PTSD has on behavioral problems among military personnel deployed to war.

\section{Additional material}

\section{Additional file 1: Psychiatric Diagnosis Status and Demotions in Deployed and Non-War Deployed Marines. Multivariate Cox Proportional Hazards Regression Analysis Examining Associations of Psychiatric Diagnosis Status and Demotions in Two Cohorts of Marine Corps Personnel, 2001-2007.}

\section{Acknowledgements}

The authors acknowledge Emily Schmied, Thierry Nedellec, Jenny Crain, Suzanne Hurtado, Scott Seggerman, Susan Hilton and CAPT David Service for their assistance in conducting this research. The authors wish to thank Science Applications International Corporation, Inc., for its contributions to this study.

\section{Author details}

${ }^{1}$ Behavioral Science and Epidemiology Program, Naval Health Research Center, San Diego, California, USA. ${ }^{2}$ Department of Family and Preventive Medicine and Moores UCSD Cancer Center, University of California, San Diego, California, USA.

\section{Authors' contributions}

$\mathrm{RMH}$ assisted in developing study design, performed the data analysis, and drafted the manuscript. GEL conceived of the study, developed the study design, and assisted in drafting the manuscript. SBK participated in the data analysis and interpretation, and helped to draft the manuscript. CFG consulted on the study methodology, interpreted the data, and made extensive revisions to the manuscript. All authors read and approved the final manuscript.

\section{Competing interests}

The authors declare that they have no competing interests.

Received: 11 November 2009 Accepted: 25 October 2010 Published: 25 October 2010

\section{References}

1. Smith TC, Ryan MAK, Wingard DL, Kritz-Silverstein D, Slymen DJ, Sallis JF, for the Millennium Cohort Study Team: New onset and persistent symptoms of post-traumatic stress disorder self reported after deployment and combat exposures: prospective population based U.S. military cohort study. Br Med J 2008, 336:366-71.

2. Hoge CW, Auchterlonie JL, Milliken CS: Mental health problems, use of mental health services, and attrition from military service after returning from deployment to Iraq or Afghanistan. JAMA 2006, 295:1023-32.

3. Mills KL, Teesson M, Ross J, Peters L: Trauma, PTSD, and substance use disorders: findings from the Australian National Survey of Mental Health and Well-Being. Am J Psychiatry 2006, 163(4):652-8.

4. Carollo R: Suspect soldiers: Troubled histories follow some troops to Iraq war. Sacramento Bee 2008 [http://www.sacbee.com/101.v-print/story/ 1077029.html], (accessed 12 Jan 2009).

5. Hersh SM: Torture at Abu Ghraib. American soldiers brutalized Iraqis. How far up does the responsibility go? New Yorker 2004 [http://www. newyorker.com/archive/2004/05/10/040510fa_fact ], (accessed 12 Jan 2009).

6. Rowe P: Military misconduct during international armed operations: 'bad apples' or systematic failure? J Conflict and Security Law 2008, 12(2):165-89.

7. Sontag $D$, Alvarez L: Across America, deadly echoes of foreign battles. New York Times 2008 [http://www.nytimes.com/2008/01/13/us/13vets.html], (accessed 18 Nov 2008). 
8. Boscarino J: Current excessive drinking among Vietnam veterans: a comparison with other veterans and non-veterans. Int J Soc Psychiatry 1981, 27:204-12

9. Yager T, Laufer R, Gallops M: Some problems associated with war experience in men of the Vietnam generation. Arch Gen Psychiatry 1984, 41:327-33.

10. Beckham JC, Feldman ME, Kirby AC, Hertzberg MA, Moore SD: Interpersonal violence and its correlates in Vietnam veterans with chronic posttraumatic stress disorder. J Clin Psychol 1997, 53:859-69.

11. Resnick H, Foy D, Donahoe C, Miller EN: Antisocial behavior and posttraumatic stress disorder in Vietnam veterans. J Clin Psychol 1989, 45:860-67.

12. Rothberg JM, Koshes RJ, Shanahan J, Christman K: Desert shield deployment and social problems on a U.S. Army combat support post. Mil Med 1994, 159:246-8.

13. Bray RM, Hourani LL, Rae Olmsted KL, Witt M, Brown JM, Pemberton MR, Marsden ME, Marriott B, Scheffler S, Vandermaas-Peeler R: 2005 Department of Defense Survey of Health Related Behaviors Among Active Duty Military Personnel Research Triangle Park, NC: Research Triangle Institute (Report RTI/ 7841/106-FR); 2006.

14. Killgore WDS, Cotting DI, Thomas JL, Cox AL, McGurk D, Vo AH, Castro CA, Hoge CW: Post-combat invincibility: violent combat experiences are associated with increased risk-taking propensity following deployment. J Psychiatr Res 2008, 42:1112-21.

15. Milliken CS, Auchterlonie JL, Hoge CW: Longitudinal assessment of mental health problems among active and reserve component soldiers returning from the Iraq War. JAMA 2007, 298(18):2141-8.

16. Collins JJ, Bailey SL: Traumatic stress disorder and violent behavior. J Trauma Stress 1990, 3(2):203-20.

17. Fontana A, Rosenheck R: The role of war-zone trauma and PTSD in the etiology of antisocial behavior. J Nerv Ment Dis 2005, 193(3):203-9.

18. Hartl TL, Rosen CS, Lee T, Drescher K, Crawford E, Wilson KA: Predicting high risk-behaviors in combat veterans with posttraumatic stress disorder. J Nerv Ment Dis 2005, 193:464-72.

19. McFall M, Fontana A, Raskind M, Rosenheck R: Analysis of violent behavior in Vietnam combat veteran psychiatric inpatients with posttraumatic stress disorder. J Trauma Stress 1999, 12(3):501-17.

20. Black DW, Carney CP, Peloso PM, Woolson RF, Letuchy E, Doebbeling BN: Incarceration and veterans of the first Gulf War. Mil Med 2005, 170:612-8.

21. Kulka RA, Schlenger WE, Fairbank JA, Hough RL, Jordan BK, Marmar CR, Weiss DS, Grady DA, Cranston A: Trauma and the Vietnam War generation: report of findings of the National Vietnam Readjustment Study New York: Brunner/Mazel; 1990, 139-86.

22. Reifman A, Windle M: Vietnam combat exposure and recent drug use: a national study. J Trauma Stress 1996, 9(3):557-68.

23. Boman B: Combat stress, post-traumatic stress disorder, and associated psychiatric disturbance. Psychosomatics 1986, 27:567-73.

24. Erickson SK, Rosenheck RA, Trestman RL, Ford JD, Desai RA: Risk of incarceration between cohorts of veterans with and without mental illness discharged from inpatient units. Psychiatr Serv 2008, 59:178-83.

25. Koenen KC, Lyons MJ, Goldberg J, Simpson J, William WM, Toomey R, Eisen SA, True W, Tsuang MT: Co-twin control study of relationships among combat exposures, combat-related PTSD, and other mental disorders. J Trauma Stress 2003, 16(5):433-8.

26. Beckham JC, Feldman ME, Kirby AC: Atrocities exposure in Vietnam combat veterans with chronic posttraumatic stress disorder: relationship to combat exposure, symptom severity, guilt and interpersonal violence. J Trauma Stress 1998, 11(4):777-85.

27. American Psychiatric Association: Diagnostic and Statistical Manual of Mental Disorders. Washington, DC: American Psychiatric Association; Fourth 2000, Text Revision.

28. Therneau TM, Grambasch PM: Modeling survival data: Extending the Cox Model. New York: Springer-Verlag; 2000

29. Armed Forces Health Surveillance Center: Relationships between the nature and timing of mental disorders before and after deploying to Iraq/Afghanistan, active component, U.S. Armed Forces, 2002-2008. Medical Surveillance Monthly Report (MSMR) 2009, 16(2):2-6.

30. Brady KT, Back SE, Coffey SF: Substance abuse and posttraumatic stress disorder. Curr Dir Psychol Sci 2004, 13(5):206-9.

31. McFarlane A: The contribution of epidemiology to the study of traumatic stress. Soc Psychiatry Psychiatr Epidemiol 2004, 39(11):874-82.
32. Cuffel BJ, Shumway M, Chouljian TL, Macdonald T: A longitudinal study of substance use and community violence in schizophrenia. J Nerv Ment Dis 1994, 182(12):704-8

33. Swanson JW, Holzer CE III, Ganju VK, Jono RT: Violence and psychiatric disorder in the community: evidence from the Epidemiologic Catchment Area surveys. Hosp Community Psychiatry 1990, 41(7):761-70.

34. Tessler R, Dennis D: A synthesis of NIMH-funded research concerning persons who are homeless and mentally ill. Washington, DC: US Department of Health and Human Services; 1989.

35. Naifeh JA, North TC, Davis $\lrcorner$, Reyes G, Logan CA, Elhai JD: Clinical profile differences between PTSD-diagnosed military veterans and crime victims. J Trauma Dissociation 2008, 9(3):321.

36. MacNair RM: Perpetration-induced traumatic stress in combat veterans. Peace and Conflict: Journal of Peace Psychology 2002, 8:63-72.

37. Iversen AC, Fear NT, Ehlers A, Hacker Hughes J, Hull L, Earnshaw M, Greenburg N, Rona R, Wessely S, Hotopf : Risk factors for post-traumatic stress disorder among UK Armed Forces personnel. Psychol Med 2008, 38:511-22.

38. Orth U, Wiland E: Anger, hostility, and posttraumatic stress disorder in trauma-exposed adults: a meta-analysis. J Consult Clin Psychol 2006, 74(4):698-706.

39. Laufer RS, Brett E, Gallops M: Symptom patterns associated with posttraumatic stress disorder among Vietnam veterans exposed to war trauma. Am J Psychiatry 1985, 142:1304-11.

40. Noonan ME, Mumola CJ: Veterans in state and federal prison, 2004 Bureau of Justice Statistics: Special Report Rockville, MD: U.S. Department of Justice (NCJ217199); 2007.

41. CNO Study Group: CNO study group's report on equal opportunity in the Navy. Washington, DC: Department of the Navy; 1998

42. Culbertson AL, Magnusson P: An Investigation into Equity in Navy Discipline (NPRDC-TR-92-17). San Diego, CA: Navy personnel Research and Development Center; 1992.

43. Edwards JE, Knouse SB: Racial- and ethinic-group differences in characterof-separation and disciplinary rates among first-term enlistees who are ineligible to reenlist (NPRDC-TN-91-1). San Diego, CA: Navy personnel Research and Development Center; 1991.

44. Edwards JE, Newell CE: Navy pattern-of-misconduct discharges: A study of potential racial effects (NPRDC-TR-94-11). San Diego, CA: Navy personnel Research and Development Center; 1994.

\section{Pre-publication history}

The pre-publication history for this paper can be accessed here: http://www.biomedcentral.com/1471-244X/10/88/prepub

doi:10.1186/1471-244X-10-88

Cite this article as: Highfill-McRoy et al:: Psychiatric diagnoses and punishment for misconduct: the effects of PTSD in combat-deployed Marines. BMC Psychiatry 2010 10:88.

\section{Submit your next manuscript to BioMed Central and take full advantage of:}

- Convenient online submission

- Thorough peer review

- No space constraints or color figure charges

- Immediate publication on acceptance

- Inclusion in PubMed, CAS, Scopus and Google Scholar

- Research which is freely available for redistribution

Submit your manuscript at www.biomedcentral.com/submit
Biomed Central 